\title{
ASSOCIATION OF GLYCATED HAEMOGLOBIN WITH LIPID PROFILE IN TYPE 2 DIABETES PATIENTS
}

\author{
Vithpala Praveena1, Sreedevi N. $N^{2}$
}

${ }^{1}$ Assistant Professor, Department of Biochemistry, ESIC Medical College, Hyderabad.

${ }^{2}$ Assistant Professor, Department of Biochemistry, NIMS, Punjagutta, Hyderabad, Telangana.

\begin{abstract}
BACKGROUND

Diabetes mellitus is one of the common metabolic disorders. It has become a global pandemic with prevalence in both developing and developed countries. Glycated haemoglobin (HbA1c) is used to assess long-term glycaemic control. It indicates the mean plasma glucose level over three months. Patients with type 2 diabetes have an increased prevalence of lipid abnormalities. Dyslipidaemia increases the risk of cardiovascular and cerebrovascular attacks owing to atherosclerosis, controlling hyperglycaemia reduces $\mathrm{HbA1c}$ levels and reduces risk of complications resulting due to hyperglycaemia.

This study was done to find any association between HbA1c and lipid profile, and thereby HbA1c can be used for screening high risk patients to diagnose dyslipidaemia and timely intervention can avoid complication.
\end{abstract}

\section{MATERIALS AND METHODS}

This is a descriptive study comprising of 80 non-hypertensive patients with diabetes aged 30 - 60 yrs. attending OPD Department at Mahavir Institute of Medical Sciences with no history of cardiovascular, thyroid, renal or any other organ disorders. The patients were classified into two groups depending on their glycated haemoglobin (HbA1c) as controlled (A1c $<7 \%)$ and uncontrolled (A1c $>7 \%$ ) as per ADA guidelines.

\section{RESULTS}

The study included 80 patients. They were further subdivided into two groups based on HbA1c (Group I $<7 \%$ and Group II $>7 \%$ ). Mean \pm S.D. of fasting glucose $(\mathrm{mg} / \mathrm{dL})$, total cholesterol $(\mathrm{mg} / \mathrm{dL})$, triglycerides $(\mathrm{mg} / \mathrm{dL}), \mathrm{LDL}-\mathrm{C}(\mathrm{mg} / \mathrm{dL}), \mathrm{VLDL}(\mathrm{mg} / \mathrm{dL}) \mathrm{between}$ Group I and II were (117 \pm 18.44 vs. $162 \pm 37.66)$, ( $150.4 \pm 38.26$ vs. $175.6 \pm 52.26)$, (118 \pm 43.92 vs. $170 \pm 99.35)$, (84.8 \pm 29.87 vs. $105.64 \pm 36.22),(23.51 \pm 8.64$ vs. $34.13 \pm 20.04)$ respectively with a statistical significant association of HbA1c with TG, LDL lipid parameter.

\section{CONCLUSION}

Lipid parameters especially cholesterol, triglycerides and LDL-C were raised in uncontrolled group. Significant association between HbA1c and lipid parameters, Triglycerides and LDL were observed. With proper glycaemic control dyslipidaemia can be avoided, thereby reducing risk of atherosclerosis.

\section{KEYWORDS}

HbA1c, Diabetes Mellitus, Lipid Profile, Glycated Haemoglobin.

HOW TO CITE THIS ARTICLE: Praveena V, Sreedevi N. N. Association of glycated haemoglobin with lipid profile in type 2 diabetes patients. J. Evolution Med. Dent. Sci. 2018;7(04):445-448, DOI: 10.14260/jemds/2018/99

\section{BACKGROUND}

Diabetes is a group of metabolic diseases characterised by hyperglycaemia resulting from defects in insulin secretion, insulin action or both. The chronic hyperglycaemia of diabetes is associated with long-term damage, dysfunction and failure of different organs. ${ }^{1}$

WHO has declared India as "Diabetic Capital of the World." 2 The prevalence of diabetes for all age groups worldwide was estimated to be $2.8 \%$ in 2000 and $4.4 \%$ in 2030. The total number of people with diabetes is projected to rise from 171 million in 2000 to 366 million in 2030.3 Diabetes causes about $5 \%$ of all deaths globally each year. The chronic hyperglycaemia is associated with damage of heart, kidneys, nerves and blood vessels.

'Financial or Other Competing Interest': None.

Submission 27-12-2017, Peer Review 09-01-2018,

Acceptance 11-01-2018, Published 22-01-2018.

Corresponding Author:

Dr. Vithpala Praveena,

2-2-24/BL/15/6,

DD Colony, Bagh Amberpet,

Hyderabad-13.

E-mail: praveenavithpala@gmail.com

DOI: $10.14260 /$ jemds/2018/99

(c) (i) $($ )
$50 \%$ of patients with diabetes die of cardiovascular disease. ${ }^{4}$ Although, the prevalence of both type 1 and type 2 $\mathrm{DM}$ is increasing, type $2 \mathrm{DM}$ is expected to rise more rapidly because of increased obesity and environmental effects and reduced activity levels. The risk of complications increases with duration of hyperglycaemia. Insulin resistance is a major defect in diabetes mellitus that result in development of lipid abnormalities by altering the enzymatic pathways and key enzymes involved in lipid metabolism, therefore increasing the risk of CHD. ${ }^{5}$ The chronic complications of DM affect many organ systems and are responsible for the majority of morbidity and mortality associated with the disease. Disorders of lipid metabolism are common and prominent in diabetes and are important risk factors for the high frequency of atheromatous complications in the disease. ${ }^{6}$ On national survey in India, $54 \%$ of diabetics developed complications in the most productive years of their lives before the age of 50 years. ${ }^{7}$ Glycated haemoglobin (HbA1c) is routinely used as a diagnostic method for measuring long-term glycaemic control. HbA1c fraction of Haemoglobin attached to glucose indicates the mean blood glucose level. HbA1c can predict the risk for the development of diabetic complications in diabetes patients. The UKPDS study has shown that in patients with type 2 diabetes, diabetic complications were strongly 
associated with previous hyperglycaemia. Glycaemic control with decreased level of $\mathrm{HbA} 1 \mathrm{c}$ is likely to reduce the risk of complications. ${ }^{8}$ Elevated $\mathrm{HbA} 1 \mathrm{c}$ has been regarded as an independent risk factor for coronary heart disease (CHD) and stroke in subjects with or without diabetes. ${ }^{9}$ In patients of type 2 Diabetes mellitus, hyperglycaemia increases the risk of microvascular complications, while dyslipidaemia is a major risk factor for macrovascular complications.8,10

A few studies have previously tried to find the correlation between HbA1c levels and lipid profile. Some of these have shown that all the parameters of lipid profile have significant correlation with glycaemic control.11,12

On the other hand, some studies do not report significant correlation between glycaemic control and all parameters of lipid profile. 13

The Diabetes Complications and Control Trial (DCCT) established glycosylated haemoglobin (HbA1C) as the gold standard of glycaemic control with levels $<7 \%$ deemed appropriate for reducing the risk of vascular complications. ${ }^{14}$ Elevated $\mathrm{HbA} 1 \mathrm{c}$ has been regarded as an independent risk factor for coronary heart disease (CHD) and stroke in subjects with or without diabetes.

\section{MATERIALS AND METHODS}

A Descriptive study of total 80 type 2 diabetic patients attending OPD of Mahavir Institute of Medical Sciences, Vikarabad, Telangana from September 2015 to January 2016 were included in the study.

For sample collection following criteria is used.

\section{Inclusion Criteria}

Patients with known history of diabetes of $<4$ yrs.

\section{Exclusion Criteria}

Type I diabetes mellitus, patients with hepatic or renal disorder, pregnancy, lactation, anaemia, thyroid disorder.

Fasting venous blood samples were collected from the subjects for estimating lipid profile and plasma glucose. After centrifugation, plasma fasting glucose and serum lipid profile were estimated. Fasting plasma glucose (FPG) is estimated by hexokinase method. Total Cholesterol, (TC), HDL-Cholesterol (HDL-C) and triglycerides (TG) were processed in automated analyser, LDL-cholesterol and VLDL were calculated by Friedwald and Fredrickson formula. TC/HDL and HDL/LDL ratio were calculated. HbA1c was estimated by Ion exchange chromatography. Reference intervals for lipid profile are considered as per NCEP-ATP III guidelines. TC $>200 \mathrm{mg} / \mathrm{dL}$, $\mathrm{TG}>150 \mathrm{mg} / \mathrm{dL}, \mathrm{LDL}>100 \mathrm{mg} / \mathrm{dL}$ and $\mathrm{HDL}<40 \mathrm{mg} / \mathrm{dL}$ are considered abnormal. Dyslipidaemia is defined by presence of one or more than one abnormal serum lipid concentration. As per ADA criteria, HbA1c $>7 \%$ is considered as poor control in diabetic patients. The data was evaluated with GraphPad Prism 7 software. Mean, S. D (Standard deviation), SEM (Standard Error of Mean) was calculated and unpaired ttest was done.
Results were expressed as Mean \pm S.D. P value $<0.05$ was considered as statistically significant.

\section{RESULTS}

\begin{tabular}{|c|c|c|c|}
\hline \multicolumn{4}{|c|}{ Glycated Haemoglobin (HbA1c) } \\
\hline Parameter & $\begin{array}{c}\leq 7.0(n=40) \\
\text { Group I }\end{array}$ & $\begin{array}{c}>7.0(n=40) \\
\text { Group II }\end{array}$ & P-value \\
\hline & Mean \pm S.D & Mean \pm S.D & \\
\hline $\begin{array}{c}\text { TC (Total } \\
\text { Cholesterol) }\end{array}$ & $150.4 \pm 38.26$ & $175.6 \pm 52.26$ & 0.016 \\
\hline $\begin{array}{c}\text { TG } \\
\text { (Triglycerides) }\end{array}$ & $118 \pm 43.92$ & $170 \pm 99.35$ & 0.003 \\
\hline $\begin{array}{l}\text { HDL-C (High } \\
\text { Density } \\
\text { Lipoprotein) }\end{array}$ & $42.3 \pm 9.38$ & $40.71 \pm 8.91$ & 0.44 \\
\hline $\begin{array}{l}\text { LDL-C (Low } \\
\text { Density } \\
\text { Lipoprotein) }\end{array}$ & $84.8 \pm 29.87$ & $105.64 \pm 36.22$ & 0.006 \\
\hline $\begin{array}{l}\text { Risk Ratio } \\
\text { (TC/HDL-C) }\end{array}$ & $3.51 \pm 0.97$ & $4.39 \pm 1.13$ & 0.0004 \\
\hline $\begin{array}{c}\text { VLDL (Very Low } \\
\text { Density } \\
\text { Lipoprotein) }\end{array}$ & $23.51 \pm 8.64$ & $34.13 \pm 20.04$ & 0.002 \\
\hline LDL-C/ HDL-C & $2.1 \pm 0.87$ & $2.5 \pm 0.94$ & 0.02 \\
\hline $\begin{array}{c}\text { FPG (Fasting } \\
\text { Plasma Glucose) }\end{array}$ & $117.62 \pm 18.44$ & $162.9 \pm 37.66$ & 0.0001 \\
\hline Table 2. Biochen & $\begin{array}{l}\text { al Parame } \\
\text { caemic Co }\end{array}$ & $\begin{array}{l}\text { rs Categorise } \\
\text { ol (HbA1c) }\end{array}$ & Tact \\
\hline
\end{tabular}

The study included 80 patients. They were further subdivided into two groups based on HbA1c (Group I $<7 \%$ and Group II $>7 \%)$. Mean \pm S.D of Fasting glucose $(\mathrm{mg} / \mathrm{dL})$ Total cholesterol (mg/dL), Triglycerides $(\mathrm{mg} / \mathrm{dL})$, LDL-C $(\mathrm{mg} / \mathrm{dL})$, VLDL $(\mathrm{mg} / \mathrm{dL})$ between Group I and II were $(117 \pm$ 18.44 vs. $162 \pm 37.66),(150.4 \pm 38.26$ vs. $175.6 \pm 52.26)$, (118 \pm 43.92 vs. $170 \pm 99.35),(84.8 \pm 29.87$ vs. $105.64 \pm 36.22)$, (23.51 \pm 8.64 vs. $34.13 \pm 20.04)$ respectively with a statistical significant difference between the groups.

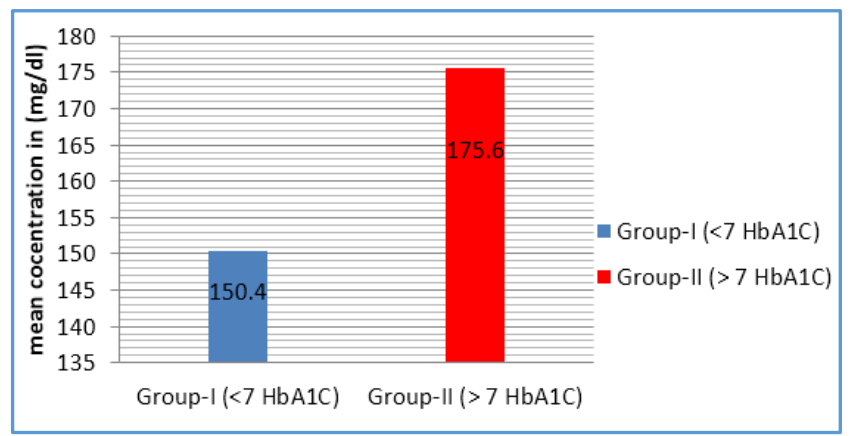

Comparison of Mean Values of Lipid Parameters in Two Groups Mean Values of T. Cholesterol (TC) between the Two Groups 


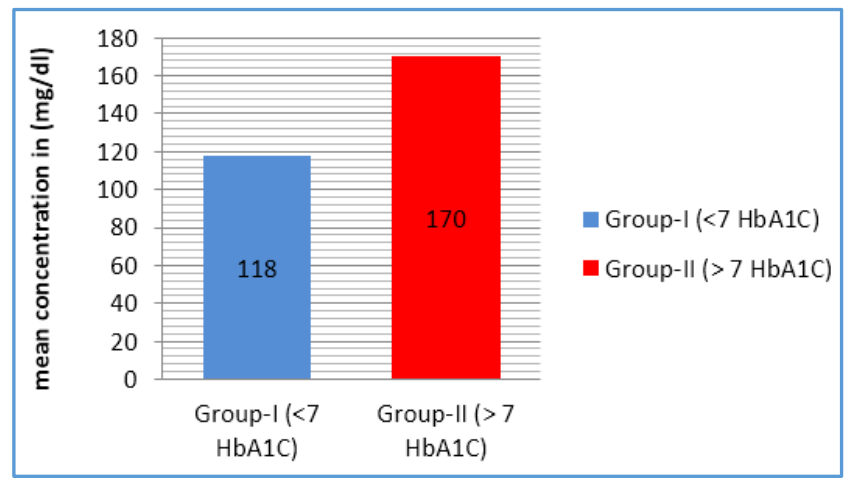

Mean Values of Triglycerides (TG) between the Two Groups

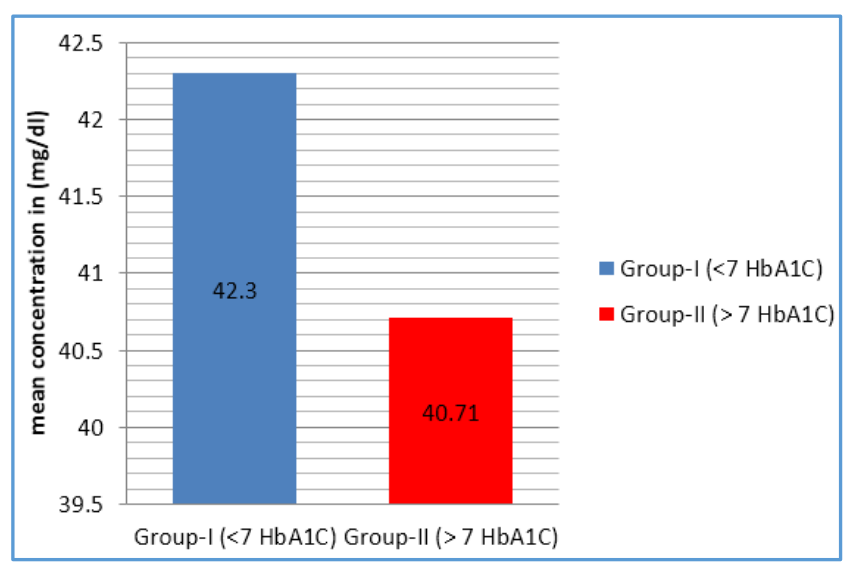

Mean Values of HDL-C (High Density Cholesterol) between the Two Groups

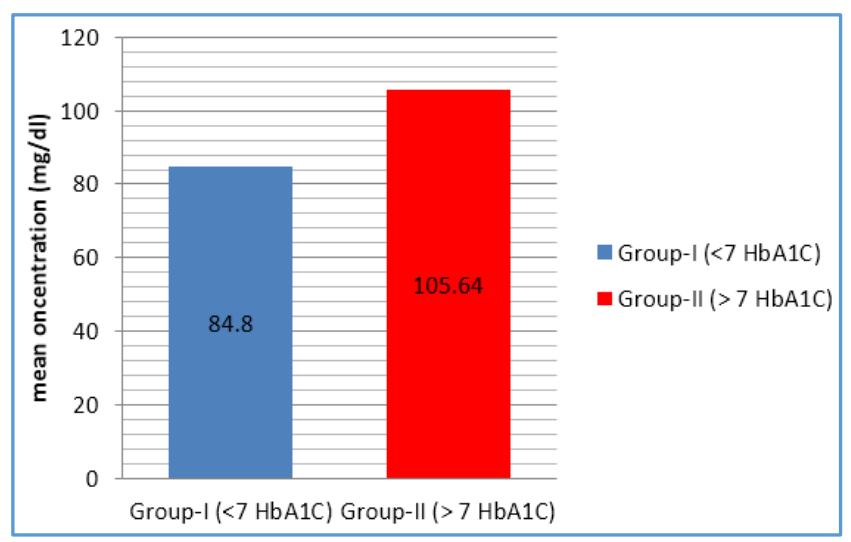

Mean Values of LDL-C (Low Density Cholesterol) between the Two Groups

\section{DISCUSSION}

In this study, type 2 diabetic patients with no other complications are divided into 2 groups as Group I with HbA1c $\leq 7.0 \%$ and Group II with HbA1c $>7.0 \%$ as per ADA guidelines and $\mathrm{HbA} 1 \mathrm{c}$ of $<7.0 \%$ is considered good control in diabetic patients. It is observed with results of triglycerides, LDL-C and TC average is more in Group II subjects when compared to Group I patients. But no significant difference in HDL average mean in two groups was noted. Fasting glucose mean in Group II patients is high when compared to Group I patients' association of HbA1c with FPG statistically highly significant. The association of HbA1c with Triglycerides (TG) was positive and significant $(\mathrm{P}=0.003)$, and with LDL-C $(\mathrm{P}=0.006)$ is significant with TC ( $\mathrm{p}$-value $=0.016)$. Statistically association is seen, but weak when compared to TG and with that of HDL-C no statistically significant association is seen.

This descriptive study was done to find out the pattern of lipid profile in type 2 diabetic patients with good and poor control and with no other organ complication. In the study it is observed that fasting glucose, triglycerides and total cholesterol are significantly high in Group II subjects when compared to Group I. This indicates patients with uncontrolled diabetes have dyslipidaemia when compared to patients with controlled sugars. The present study demonstrates that TC, TG and LDL-C increases with increased HbA1c values. Findings are in agreement with previous studies. $12,15,16,17$

Therefore, better glycaemic control through lifestyle modification and anti-diabetic therapy can reduce the risk of dyslipidaemia, thereby reducing the risk of development of atherosclerosis and related complications. It has been estimated that reducing the $\mathrm{HbA} 1 \mathrm{c}$ level by $0.2 \%$ could lower the mortality by $10 \% .18$

High levels of triglycerides and cholesterol in uncontrolled hyperglycaemia can be due to effect of insulin on the liver apolipoprotein production. It regulates the enzymatic activity of lipoprotein lipase (LpL) and cholesterol ester transport protein. All these factors are likely to be responsible for dyslipidaemia in Diabetes mellitus. ${ }^{19}$

\section{CONCLUSION}

In this study, we compared various parameters of lipid profile in two groups (one with controlled and the other with uncontrolled hyperglycaemia) by using HbA1c levels as an indicator of glycaemic control. Lipid parameters especially cholesterol, triglycerides and LDL-C were raised in uncontrolled group.

Significant association between $\mathrm{HbA1c}$ and lipid parameters were observed. Thus, HbA1c can be used as a potential predictor of dyslipidaemia in type 2 diabetic patients to initiate early treatment and thereby reducing the occurrence of cardiovascular and cerebrovascular events.

Studies show that by improving glycaemic control, the risk of cardiovascular events can be minimised in diabetics. 18,20

\section{REFERENCES}

[1] American Diabetes Association. Diagnosis and classification of diabetes mellitus. Diabetes Care 2010;33(Suppl 1):S62-9.

[2] Gupta V, Suri P. Diabetes in elderly patients. JK Practitioner 2002;91(4):258-9.

[3] Wild S, Roglic G, Green A, et al. Global prevalence of diabetes. Diabetes Care 2004;27(5):1047-53.

[4] Carneiro AV. Coronary heart disease in diabetes mellitus: risk factor and epidemiology. Rev Port Cardiol 2004;23(10):1359-66.

[5] Taskinen MR. Diabetic dyslipidemia. Atheroscler Suppl 2002;3(1):47-51.

[6] Amos AF, McCarty DJ, Zimmet P. The rising global burden of diabetes and its complications: estimates and projections to the year 2010. Diabet Med 1997;14(Suppl 5):S1-85. 
[7] Ramaiya KL, Kodali VR, Alberti KG. Epidemiology of diabetes in Asians of the Indian subcontinent. Diabetes Metab Rev 1990;6(3):125-46.

[8] Stratton IM, Alder AI, Neil HA, et al. Association of glycaemia with macrovascular and microvascular complications of type 2 diabetes (UKPDS 35): prospective observational study. BMJ 2000;321(7258):405-12.

[9] Selvin E, Coresh J, Golden SH, et al. Glycemic control and coronary heart disease risk in persons with and without diabetes: the atherosclerosis risk in communities study. Arch Intern Med 2005;165(16):1910-6.

[10] Turner RC, Millns H, Neil HA, et al. Risk factors for coronary artery disease in non-insulin dependent diabetes mellitus: United Kingdom prospective diabetes study (UKPDS: 23). BMJ 1998;316(7134):823-8.

[11] Ramona G, Loan C, Simona T, et al. Relationship between glycosylated hemoglobin and lipid metabolism in patients with type 2 diabetes. Studia Universitatis "Vasile Goldiş" Seria Ştiinţele Vieţii 2011;21(2):313-8.

[12] Bal BS, Salwan SK, Chandarana U. Study of association between HbA1c level and lipid profile in type 2 diabetes mellitus. Annals of International Medical and Dental Research 3(2):36-9.

[13] Yan Z, Liu Y, Huang H. Association of glycosylated hemoglobin level with lipid ratio and individual lipids in type 2 diabetic patients. Asian Pac J Trop Med 2012;5(6):469-71.
[14] Rohlfing CL, Wiedmeyer HM, Little RR, et al. Defining the relationship between plasma glucose and $\mathrm{HbA}(1 \mathrm{c})$ : analysis of glucose profiles and $\operatorname{HbA}(1 \mathrm{c})$ in the diabetes control and complications trial. Diabetes Care 2002;25(2):275-8.

[15] Meenu J, Jayendrasinh JM, Neeta M. Correlation between HbA1c values and lipid profile in type 2 diabetes mellitus. International Journal of Basic and Applied Physiology 2(1):47-50.

[16] Mahato RV, Gyawali P, Raut PP, et al. Association between glycaemic control and serum lipid profile in type 2 diabetic patients: glycated haemoglobin as a dual biomarker. Biomedical Research 2011;22(3):37580.

[17] Rajeswari S, Kumar A, Gandhi M, et al. Association between lipid profile and liver function tests in diabetic patient. International Journal of Pure \& Applied Biosciences 2014;2(4):26-31.

[18] Khaw KT, Wareham N, Luben R, et al. Glycated haemoglobin, diabetes, and mortality in men in Norfolk cohort of european prospective investigation of cancer and nutrition (EPIC-Norfolk). BM] 2001;322(7277):15-8.

[19] Goldberg IJ. Lipoprotein lipase and lipolysis: central roles in lipoprotein metabolism and atherogenesis. J Lipid Res 1996;37(4):693-707.

[20] Selvin E, Wattanakit K, Steffes MW, et al. HbA1C and peripheral arterial disease in diabetes: the Atherosclerosis Risk in Communities study. Diabetes Care 2006;29(4):877-82. 